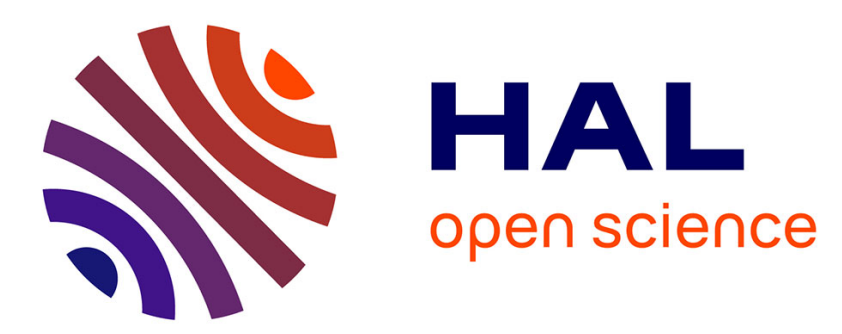

\title{
Culture et jeunes : la carpe et le lapin des territoires ruraux?
}

\author{
Hélène Chauveau
}

\section{To cite this version:}

Hélène Chauveau. Culture et jeunes : la carpe et le lapin des territoires ruraux ?. Pour : enquêtes et témoignages, 2015, 226 (2), 10.3917/pour.226.0121 . hal-01697982

\section{HAL Id: hal-01697982 \\ https://hal.science/hal-01697982}

Submitted on 31 Jan 2018

HAL is a multi-disciplinary open access archive for the deposit and dissemination of scientific research documents, whether they are published or not. The documents may come from teaching and research institutions in France or abroad, or from public or private research centers.
L'archive ouverte pluridisciplinaire HAL, est destinée au dépôt et à la diffusion de documents scientifiques de niveau recherche, publiés ou non, émanant des établissements d'enseignement et de recherche français ou étrangers, des laboratoires publics ou privés. 


\section{CULTURE ET JEUNES : LA CARPE ET LE LAPIN DES TERRITOIRES RURAUX ?}

Enquête auprès de lycéens et apprentis du LEGTA de Saint-Genest Malifaux et d'organisateurs de festivals dans le Forez (Loire)

Hélène Chauveau

GREP $\mid$ « Pour »

2015/2 $\mathrm{N}^{\circ} 226$ | pages 121 à 127

ISSN 0245-9442

Article disponible en ligne à l'adresse :

http://www.cairn.info/revue-pour-2015-2-page-121.htm

\section{!Pour citer cet article :}

Hélène Chauveau, « Culture et jeunes : la carpe et le lapin des territoires ruraux ? Enquête auprès de lycéens et apprentis du LEGTA de Saint-Genest Malifaux et d'organisateurs de festivals dans le Forez (Loire) », Pour 2015/2 (N²26), p. 121-127.

DOI 10.3917/pour.226.0121

Distribution électronique Cairn.info pour GREP.

(c) GREP. Tous droits réservés pour tous pays.

La reproduction ou représentation de cet article, notamment par photocopie, n'est autorisée que dans les limites des conditions générales d'utilisation du site ou, le cas échéant, des conditions générales de la licence souscrite par votre établissement. Toute autre reproduction ou représentation, en tout ou partie, sous quelque forme et de quelque manière que ce soit, est interdite sauf accord préalable et écrit de l'éditeur, en dehors des cas prévus par la législation en vigueur en France. Il est précisé que son stockage dans une base de données est également interdit. 


\title{
Culture et jeunes : la carpe et le lapin des territoires ruraux?
}

\section{Enquête auprès de lycéens et apprentis du LEGTA de Saint-Genest Malifaux et d'organisateurs de festivals dans le Forez (Loire)}

\author{
Hélène CHAUVEAU ${ }^{1}$ \\ Lycée d'enseignement général et technologique agricole
}

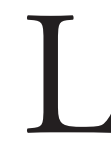
es jeunes ${ }^{2}$ sont l'avenir des territoires, entend-on souvent. En milieu rural, la majorité des acteurs, politiques, institutionnels, associatifs, économiques, sont conscients de cette réalité, surtout après plusieurs décennies durant lesquelles il a été difficile d'inciter les jeunes à rester, à revenir, ou à venir tout simplement vivre dans les villages. Aujourd'hui la tendance s'inverse : avec un immobilier moins cher correspondant à un idéal de vie différent, lieux de possibles, lieux familiers pour certains, les milieux ruraux sont perçus comme une opportunité par beaucoup de jeunes.

Mais quelle est la réalité sur place pour tous les jeunes, y compris ceux qui n'ont pas forcément choisi de vivre à la campagne ? Leur présence est-elle si désirée que cela, notamment du point de vue de leurs pratiques culturelles, qui bousculent parfois les habitudes locales. Les jeunes ruraux considèrent

\footnotetext{
1 Actuellement doctorante en Géographie Rurale, en co-tutelle entre l'Université Lumière Lyon 2 lau Laboratoire d'Études Rurales) et l'Université Fédérale du Santa-Catarina lau Laboratoire d'Agriculture Familiale, UFSC, Brésil) sur le thème des pratiques culturelles des jeunes ruraux et la requalification des territoires ruraux au Sud du Brésil, sous la direction de Claire Delfosse et Valmir Stropasolas. Cet article repose sur des travaux de Master 1 et Master 2 Études Rurales menés en 2011 dans la Loire ayant donné lieu au mémoire «Rôle des festivals culturels dans le développement local de leur territoire rural : le cas des Pays du Forez » et au dossier « Géographie des pratiques culturelles de jeunes ruraux. Enquête auprès des lycéens et apprentis du lycée agricole de Saint-Genest Malifaux ».

2 Nous entendons par « jeunes » la population ayant entre 15 et 25 ans au moment de notre enquête. Nous sommes conscients des débats autour de cette définition, voir notamment dans le numéro de la revue POUR « Initiatives des jeunes dans les espaces ruraux » $n^{\circ} 211$ de septembre 2011.
} 
souvent la ville d'un point de vue culturel, comme un lieu «branché » et cosmopolite permettant l'accès à une offre riche et variée. Mais certains montrent, par leurs pratiques, que vivre à la campagne n'exclut pas de la culture, parce qu'il est aujourd'hui facile de se rendre en ville pour profiter de ses atouts, et parce que les milieux ruraux sont traversés de multiples dynamiques culturelles, singulières et alternatives.

Nous nous appuyons ici sur deux enquêtes, que nous avons menées en 2011. L'une de plusieurs mois était centrée sur dix festivals se déroulant dans le Fore $^{3}$, dont deux étaient organisé par des «Club de jeunes ». L'autre enquête a été réalisée en 2012 sur un temps court auprès de 81 lycéens et apprentis du LEGTA de Saint-Genest Malifaux ${ }^{4,}$ par questionnaires assortis de 13 entretiens plus approfondis par groupes de deux ou trois jeunes. Ces enquêtes, bien que très différentes, ont toutes deux révélé des spécificités du lien entre culture et jeunes en milieu rural, un lien tour à tour malmené, distendu, instrumentalisé, questionné, fragilisé, mais un lien qui sans nul doute peut constituer un point fort de ces territoires.

\section{Une rencontre difficile}

Pour l'enquête sur les jeunes ruraux et la culture, menée dans le Pilat, nous avions choisi les lycéens et apprentis d'un lycée agricole pour la vision a priori singulière que ces élèves auraient du monde rural. En effet, les élèves rencontrés avaient en commun le gồt pour le milieu rural, et ce sont eux qui vont peupler les campagnes, y travailler et y vivre. Ce que cela implique en termes de pratiques culturelles nous intéressait. Certains de ces jeunes étaient fiers de vivre en milieu rural et revendiquaient une vraie identité rurale, avec des « je n'aime pas la ville, le bruit et le monde » en quantité. Les justifications par le calme et l'isolement sont fréquentes avec la recherche du "repli domestique " (Gambino, 2008) qui ne paraît pas vraiment pouvoir se marier avec une vie de pratiques culturelles intenses. De fait, les apprentis et lycéens rencontrés à Saint-Genest-Malifaux ne sont pas des habitués des "lieux culturels » de la région. 76 des 81 jeunes interrogés estiment " fréquenter peu les lieux culturels " et à la question " allez-vous ", les jeunes ont répondu qu'ils allaient " jamais ou très rarement " dans un festival (63 sur 81), à un concert (67 sur 81), voir un spectacle (66 sur 81) et au musée (63 sur 81). Plus de la moitié d'entre eux déclare donc ne " jamais aller ou très rarement " dans ces quatre lieux culturels. Presque tous les élèves interrogés assistent hebdomadairement

3 Territoire rural de la Loire situé au nord de Saint-Étienne, se partageant entre une plaine en voie de périurbanisation et des plateaux présentant une basse densité démographique et des activités rurales (élevage, viticulture).

4 Située dans le Pilat, territoire Parc Naturel Régional au sud-ouest de Saint-Étienne dans le département de la Loire, cette commune, profitant de l'expansion de l'agglomération stéphanoise, compte presque 3000 habitants. Le lycée agricole accueille 168 jeunes venant en majorité de milieux ruraux mais aussi de moyennes ou grandes villes ou de leur zone périurbaine, de la Haute-Loire à Lyon en passant par les banlieues stéphanoises et le Forez. 
à des films et écoutent de la musique quotidiennement ; en revanche $80 \%$ des élèves ne vont jamais ou rarement au concert ou à un festival et le même pourcentage va moins de 10 fois par an au cinéma.

Lors des entretiens les jeunes apprentis et lycéens ne disent pas se sentir lésés par leur lieu de vie, mais si " être rural ne [les] empêche pas d'accéder à la culture » ils ne fréquentent pas beaucoup les lieux culturels pour autant et sont insatisfaits de l'offre locale 5 . On observe ainsi chez certains jeunes enquêtés un désintérêt : 29 d'entre eux répondent "ça ne m’intéresse pas " à la question "Les lieux culturels : vous les fréquentez peu car ». Certains le formulent très clairement: "La culture ne mintéresse pas car j'ai pas trop le temps d'y penser, je travaille en apprentissage"; "Je vais pas tellement dans les festivals, pourtant y'en a pas mal dans le Forez, c'est vrai, mais bon moi jyy vais pas parce que ça ne mintéresse pas, c'est pas mon genre de musique [...] C'est plus personnel quoi, j’ai pas envie d'y aller mais j'ai pas l'impression d'être exclu. " Pour certains élèves, vivre en milieu rural est synonyme d'éloignement, d'isolement et d'absence d'offre culturelle : "Moi j’habite à Roanne, mais je suis interne ici la semaine et c'est pas terrible parce que y'a rien à faire ici c'est mort!». Ainsi les jeunes ruraux rencontrés ne semblent pas particulièrement amateurs de culture ou semblent trouver que la campagne n'est pas un lieu pour y exercer leurs propres pratiques.

Autre élément qui peut rendre difficile la rencontre des jeunes et de la culture en milieu rural : les représentations des pratiques culturelles des jeunes, qui pour beaucoup seraient créatrices de désordre public et de déviances. La forme festivalière, attirant du monde et parfois une population pas forcément habituelle (ou visible) en milieu rural, est la cible de ces critiques, comme le montre l'exemple des festivals du Forez qui, selon leurs responsables, font l'objet de ce type de préjugés : "Ça restera toujours aux yeux de certains un festival de jeunes, d'alcooliques et de drogués. La concentration de personnes engendre souvent ce genre d'idées" (Responsable du Foreztival en octobre 2010) ; "C'est lié aux préjugés énormes quilly a, sur le spectacle de rue, sur le mot festival [...] c'est "les sales jeunes, la drogue, le bazar" "(Responsable des Monts de la Balle en février 2011).

Mais les préjugés sont aussi dans le camp de la "culture ", avec des responsables d'événements versant parfois dans le misérabilisme à propos des jeunes ruraux. Ainsi, le responsable d'une compagnie stéphanoise installée dans le Forez rural, explique : "J'ai travaillé dans les quartiers et puis je me suis rendu compte que finalement, je voyais bien le truc arriver du "plus on allait oublier les campagnes plus on allait se prendre le boomerang dans la gueule" [...] Il y a beaucoup de choses dans les quartiers, mais dans les cambrousses au final, et bien les jeunes, à part picoler, faire du foot et avoir des voitures tuning ils font pas grandchose ». Cette image est parfois véhiculée dans les médias plus largement avec

5 Dans le questionnaire, si seuls 20 élèves répondent qu' « à Saint Genest et ses alentours il ne se passe rien culturellement », ils ne sont que 4 à dire l'inverse : «il y a ce qui vous plaît culturellement ». 19 répondent qu' "il y a des bonnes choses mais ça pourrait être mieux », et 34 estiment qu' «il y a des choses mais rien qui vous intéresse ». 
des documentaires comme ceux de la série Strip-Tease ou le, désormais culte sur la toile, "Un Samedi soir en province » de Jean-Michel Destang à propos des boites de nuits et bals itinérants dans l'Indre. Les jeunes seraient ainsi difficiles à mobiliser autour d'un projet " culturel " comme celui du festival du Volcan de Montpeloux : "Les jeunes du territoire ils ne sont là que les week-ends. Ils sont très investis dans les associations locales donc ils ne vont pas se rajouter ça. [...] On leur a proposé par exemple de tenir une buvette pendant le festival, mais ce qui les intéresse ce serait plus de faire de l'argent donc ça n'a pas fonctionné" (responsable du festival rencontrée en février 2011). Alors, qu'est-ce qui mobilise ces jeunes et quelle «culture » doit être considérée ?

\section{Un mariage prolifique}

Il faut d'abord reconsidérer ce que l'on inclut dans les « lieux de consommation culturelle " qui sont plus ruraux pour ces jeunes qu'on ne pourrait le croire. On peut dresser le même constat pour le théâtre que pour les cinémas puisque 19 élèves disent fréquenter les cinémas ruraux et urbains, 29 exclusivement les cinémas urbains et 37 exclusivement des cinémas ruraux ou salles des fêtes utilisées pour l'occasion, soit 70 \% d'habitués des salles rurales. Pour les arts vivants, 31 élèves n'en voyaient que dans des lieux ruraux contre 20 dans des théâtres urbains. Pour la musique le bilan est celui d'un mélange des sources plus grand comme le montre le schéma ci-dessous.

Figure 1 : Lieux urbains et lieux ruraux de sortie culturelle des lycéens et apprentis de Saint-Genest (réalisation et données :

H. Chauveau, novembre 2011)

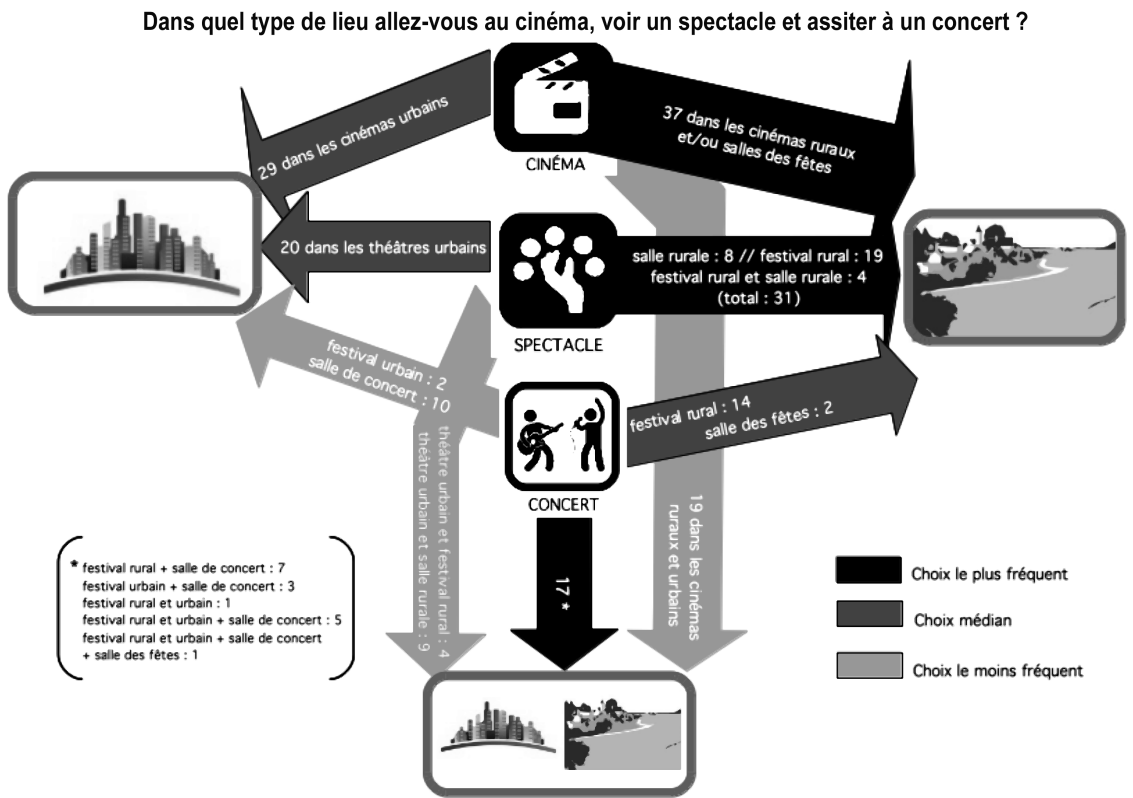


Pour les élèves de Saint-Genest, nous l'avons dit, être rural n'empêche pas d'accéder à la culture et $71 \%$ des élèves interrogés estiment que la distance ne les empêche pas d'aller à des événements culturels. Seuls 8 élèves pensent que vivre en milieu rural les prive de l'accès à certaines choses culturelles et que c'est un désavantage par rapport à la ville, alors que 34 estiment que cela donne accès aux mêmes choses, ne les prive pas de sorties. Seuls 20 élèves sur 81 estiment qu'à Saint Genest et ses alentours, il ne se passe rien culturellement et surtout, 29 disent même que vivre en milieu rural leur donne accès pas forcément à moins de choses mais à des choses différentes (mieux / moins bien), et 13 ont souligné le "mieux ${ }^{6}$ indiquant leur préférence pour les possibilités rurales. Si selon une grande majorité des jeunes interrogés, habiter en milieu rural ne change pas leur rapport à la culture, et qu'ils fréquenteraient autant (ou aussi peu) les lieux culturels s'ils habitaient en ville, d'autres points de vue émergent en revanche, qui montrent que vivre en milieu rural permet d'avoir accès à une offre culturelle singulière, qui les rend fiers, et dans tous les cas, différents. C'est le cas dans les témoignages suivants : "Je suis de montagne moi, du plateau ardéchois. Moi je trouve pas ça vide, y'a des bals par chez nous, y'a moins de boîtes mais bon [...] on reste pas enfermés quand même"; "Moi je suis de Tance en Haute-Loire, donc là c'est vraiment la campagne [...] Moi c'est plus des soirées entre amis, mais aussi des concerts, le ciné, j'aime bien partir un peu. [...] Autour de chez moi c'est bien animé ouais. Je les envie pas du tout ceux qui habitent en ville. ". On voit à travers ces témoignages s'esquisser une autre définition de la culture, comme celle des collégiens de l'article des M2PRVC dans ce même numéro.

Dernière caractéristique livrée par les apprentis et lycéens du LEGTA de Saint-Genest ; l'importance de leur investissement, qu'il soit associatif sur le temps long ou pour un événement ponctuel. Cette importance n'est pas nécessairement numérique, puisque parmi les interrogés, les élèves investis dans une association sont $39 \%$ et $18 \%$ dans un événement (de la Foire à la "Vogue » en passant par le Téléthon), mais ces chiffres sont tout de même conséquents et au-delà du quantifiable, ce sont généralement des éléments importants dans la vie de ces élèves. Les associations sportives prédominent, mais celles à activités "culturelles » sont aussi présentes et ces événements ont surtout un grand rôle dans l'animation du territoire (les festivals musicaux les plus fréquentés par nos enquêtés se déroulent tous dans des zones rurales du Pilat ou du Forez). Il s'agit là d'utiliser et développer ses « ressources autochtoniques ", sorte de " capital du pauvre" (Renahy, 2005) qui sont la condition de réussite de ces projets, et qui paraissent une spécificité forte du rural face à l'urbain, fragmenté et surchargé, une réponse en forme de s' « il n’y a rien, il

6 Parmi les 13 élèves ayant répondu dans le questionnaire «vivre en milieu rural vous donne accès pas forcément à moins de choses mais à des choses différentes » et qui ont souligné « mieux », cinq ont précisé : «c'est mieux dans les bals »; « on peut beaucoup plus s'amuser en campagne, faire du vélo, du foot... »; « Mieux bien car campagne »; « la tranquillité »; «préférence pour le rural ». 
faut bien faire soi-même " et où la vie associative est une " potentialité héritée en milieu rural » (Delfosse, 2003). Ainsi, l'histoire de l'éducation populaire et des associations rurales éclaire la compréhension du rôle actuel des festivals culturels en milieu rural, en particulier quand ceux-ci sont créés par des mouvements qui s'en revendiquent comme les deux Clubs de Jeunes (CDJ) qui organisent des festivals dans le Forez : le CDJ de Sail-sous-Couzan qui organise un petit festival punk et l'Association Pour l'Intercommunalité des Jeunes (APIJ), mère du Foreztival, bien connu dans la région.

À Sail-sous-Couzan, le château et les jeunes sont deux éléments historiques de l'offre culturelle locale : "Bercés par cette ouverture d'esprit et par ce patrimoine associatif [référence notamment aux Estivades, festival créé par Marcel Maréchal au château dans les années 1960], les jeunes de Sail ont eux aussi apporté leur pierre à l'édifice. C'est en 1993 que le Club des Jeunes et par la suite l'association "Pousse de Bambou", organise son premier Festival "Rock sous Couzan" dont il y aura huit éditions au château. Aujourd'hui le Club des Jeunes a repris ce flambeau et organise chaque année, le deuxième week-end de mai, un festival au centre culturel sur deux jours... et peut être que bientôt les pierres $d u$ château vibreront à nouveau au son des guitares électriques... " ${ }^{7}$. Si l'association en question n'existe plus, le CDJ a ses irréductibles et les différentes cohortes ${ }^{8}$ de jeunes se succèdent, même s'ils sont de moins en moins nombreux à vivre au village, et s'entraident pour maintenir un événement avec une proposition alternative : "On n'a pas de partenaires, mais les anciens nous aident. Ceux du CDJ de Sail de la génération d'avant qui faisaient le festival au château, ils sont rodés quoi [...] Ici tout le monde revient tous les week-ends et il n'y a pas grandchose à faire donc voilà, on fait ça. C'est peut-être parce qu'il n'y a rien, parce que si on était en ville avec des dizaines de bars et d'animations, on ferait sûrement pas ça» (entretien avec un membre du CDJ de Sail en mars 2011).

Pour le Foreztival, la filiation est plus concrète entre l'éducation populaire et l'association, comme nous le racontait le responsable du festival en 2011 : "L'APIJ est une association agréée d'éducation populaire affiliée aux MJC en Rhône-Alpes, créée en 1994, mise en place par les jeunes du territoire [...] Dès sa création il y avait déjà tout une dynamique des jeunes de l'intercommunalité avec tous les CDJ qui préexistaient. [...] Le premier concert vraiment soutenu par l'APIJ a été un concert pour le Téléthon, puis certains jeunes sont restés dans cette dynamique en souhaitant mettre en place un festival de grande envergure partant du constat que sur la région plus rien de ce type n'existait [...]. Toutes leurs envies et leurs objectifs furent mis à plat [dès la première réunion de préparation] : mettre en place un événement pour promouvoir la culture ici, pour promouvoir le Forez et donner leur chance aux groupes amateurs locaux"

7 Site internet de la commune de Sail-sous-Couzan consulté en avril 2011.

8 Au sens démographique d'ensemble d'individus ayant vécu un même événement au cours d'une même période, en l'occurrence ceux qui étaient jeunes dans les années 1990 et ceux qui le sont aujourd'hui. 
Dans ces deux cas, si le but est de créer un événement culturel, de la musique que l'on veut amener là parce qu'on aime ça, que l'on veut savourer et partager sa passion. L'idée de travailler ensemble autour d'un projet commun est aussi un déclencheur fort, en particulier dans ces associations de jeunes. Le rôle de ces festivals, bien que d'ampleur très différente, quant au renforcement d'une identité forézienne rurale se lit à travers la fierté que véhicule le fait d'avoir un tel événement "chez soi ", à travers la "valorisation de jeunes en quête de repères sociaux, et la contribution à la revendication identitaire de culture locales" (Benito, 2001) et la fierté de ces jeunes d'avoir porté ou de porter un jour un tel événement.

\section{La carpe et le lapin ?}

Le mariage de la carpe et du lapin ? Certainement pas, la question était rhétorique et il paraît évident que les jeunes et la culture sont plutôt l'alpha et l'oméga du développement local en milieu rural. La réalité tient d'une singularisation de l'offre et de la pratique culturelle jeune en milieu rural et d'une nécessité de reconsidérer les schémas classiques de la "culture ». Les pratiques culturelles des jeunes et la façon dont elles s'organisent sont un atout pour l'attractivité des territoires, un enjeu fort pour les différents acteurs de ces espaces qui s'intéressent à la présence et à l'investissement des jeunes à la campagne. De la honte à la fierté, du dédain à l'engagement et du mime à l'originalité, le rapport des jeunes ruraux à la culture doit être étudié dans sa complexité. La place de la mobilité dans la culture, la question du lieu lorsque l'on parle de pratique culturelle, les multiples enjeux de territoire que cette question suppose, la spatialisation et l'ancrage des jeunes sur leur territoire dans le domaine bien complexe que représente la culture, et enfin la réalité ou non d'une singularisation des pratiques selon leur ruralité ou leur urbanité sont des clefs de compréhension pour les questions de culture(s), que l'analyse des pratiques des jeunes ruraux peuvent fournir.

\section{Références}

Delfosse Claire, 2003, Géographie rurale, culture et patrimoine, HDR, Université de Lille I.

Destang Jean-Michel, Un samedi soir en province, documentaire audiovisuel, 1995 disponible sur https://vimeo.com/5163605

Gambino Mélanie, Vivre dans les espaces ruraux de faible densité de population : pratiques et représentations des jeunes dans le Périgord Vert (France) et le Rural Galway (Irlande), Thèse de géographie et d’aménagement, UMR Dynamiques Rurales, Toulouse 2 Le Mirail, 2008.

Galland Olivier, Lambert Yves, Les jeunes ruraux, Paris, Inra, L'Harmattan, 1993.

Garcia Laurence, Parcours artistiques et culturels de jeunes habitantle)s dans les perspectives et les enjeux des dynamiques rurales, en Pays Midi-Quercy, Thèse de sociologie, Toulouse 2 Le Mirail, 2012.

Renahy Nicolas, Les gars du coin : enquête sur une jeunesse rurale, La Découverte, 2005. 